\title{
Nuevas propuestas para la investigación sobre el Jesús histórico: El Jesús Recordado de James Dunn (II)
}

\author{
LuCAS Figueroa \\ Instituto Santo Cura de Ars - Mercedes - Argentina \\ figue_64@hotmail.com \\ Recibido 07.08.2020/Aprobado 10.09.2020 \\ DOI: https://doi.org/10.46553/teo.57.133.2020.p9-36
}

\section{RESUMEN}

La obra de James Dunn que se intitula El Cristianismo en sus comienzos (I): Jesús Recordado-primer volumen de su investigación sobre el primitivo cristianismo- invita a repensar la investigación del Jesús histórico desde una mejor precisión en el objeto de estudio, desde un paradigma distintivo en la historia de la Quest y desde una metodología que se alumbra desde ese cambio paradigmático. En esta segunda parte, ingresamos en las aportaciones que el autor inglés suscita desde su opera magna, que ya es una obra de referencia en el marco de la investigación de la Quest.

Palabras claves: Investigación sobre la vida de Jesús; Revelación; Historia; Fe; Hermenéutica; Paradigma

News Approaches for the Study of the Historical Jesus: The Jesus Remembered by James Dunn (II)

ABSTRACT

James Dunn's work entitled Christianity in the Making (I): Jesus Remembered - first volume of his investigation of early Christianity - invites us to rethink the investigation of the historical Jesus from a better precision in the object of study, from a distinctive paradigm in the history of the Quest and from a methodology that is illuminated from that paradigmatic change. In this second part of our article, we show the most important contributions of the English scholar. His work is a reference in the Quest of the historical Jesus.

Keywords: Quest; Revelation; History; Truth; Hermeneutics; Paradigm.

\footnotetext{
- El autor es Director de Estudios del Instituto Sacerdotal Santo Cura de Ars.
} 


\section{Racconto}

En la parte primera de esta presentación, tratamos de hacer una mostración de la situación que los métodos para la investigación acerca del Jesús histórico podían generar a partir de los presupuestos sobre los que se cimientan. Dunn postula que las tendencias en la investigación se podrían explicar en torno a las tensiones entre la fe y la historia: la elección de ampararse en uno o en otro lugar, la historia o la fe como polo exclusivo de la indagación. Sin embargo, al desentenderse de la fe que Jesús causó en sus primeros seguidores, fe histórica, las búsquedas han dejado de lado lo que realmente sucedió: Jesús y su actuación suscitaron fe. Y, por otra parte, al desentenderse de la historia, se pierde de vista la necesidad propia de una fe de Revelación histórica: su credibilidad está atada a los acontecimientos históricos. Es en este lugar donde la intención de nuestro autor se hace más clara: hay que intentar un diálogo fructuoso entre la Fe y la Historia: emerge entonces la labor hermenéutica.

Para entender el aporte del erudito inglés será necesario comprender también sus presupuestos metodológicos y sus opciones en el ámbito del descubrimiento de la figura de Jesús en el topos de su tradición. Es allí donde aparece con más fuerza su contribución, que enunciábamos - en el artículo anterior - desde tres vertientes: la del objeto formal, la de la pretensión paradigmática y la de la construcción metodológica.

\section{Presupuestos históricos y hermenéuticos}

\subsection{La situación de los estudios históricos sobre Jesús}

\subsubsection{Sentido del pasado}

La primera constatación que descubre cualquier trabajo histórico es la diferencia y la distancia que separa al historiador de los acontecimientos sucedidos. Según la perspectiva del historiador 
británico Peter Burke, lo primero que condiciona el trabajo histórico es la certeza de que estamos en un tiempo distinto, que el pasado ya no nos pertenece y no nos sentimos parte de él. ${ }^{1}$ Esta distancia y esta diferencia hacen imposible cualquier intento de "domesticar" el pasado, pues él siempre se nos presentará en algún contraste con nuestras miradas. Esta es la crítica más efectiva de la gran recensión de Schweitzer: Jesús no resistió una modernización, sino que perdió toda su fuerza. ${ }^{2}$

La distancia y la diferencia, entonces, representan la alteridad histórica entre los acontecimientos y la labor del historiador. Dicha distancia y diferencia no es algo a ser superado, como pensaba el historicismo, sino que establece el horizonte de comprensión de lo histórico.

La tendencia, al contrario, suele ser la de arrancar a Jesús de su realidad histórica y llevarlo a la época donde se investiga, como si de una sustancia llevada al laboratorio se tratase. El trabajo del investigador necesita sustraerse de tal tentación para no fabricar un cristianismo que use de Jesús sólo su "cáscara" y lo rellene con sus "contenidos":

«La cuestión es que, al menos en parte, la alteridad de Jesús es una alteridad histórica: la alteridad en particular de Jesús el judío (una vez más, algo que los 'modernos' hemos olvidado a nuestras expensas). Sin la percepción de Jesús 'nacido bajo la Ley' (Gál, 4,4), de Cristo 'hecho siervo de la circuncisión' (Rom 15,8), sin la conciencia histórica de lo que eso significó en lo relativo a peculiaridades de historia, es probable que la humanidad de Cristo sea perdida nuevamente de vista dentro del cristianismo y absorbida en una afirmación esencialmente docética de su divinidad». ${ }^{3}$

1 Cf. Peter Burke, The Reinassance Sence of the Past (Londres: Edward Arnold, 1969), 1, 19

2 Cf. Albert Schweitzer, Investigación Sobre La Vida De Jesús (Ii) (Valencia: Edicep, 2002)., 673-674.

3 James D.G. Dunn, El Cristianismo en sus comienzos (l): Jesús recordado (Navarra: Editorial Verbo Divino, 2009), 136. También señala Dunn que esta realidad, que parecía arreciar y empezar a comprenderse en la perspectiva que ponía a Jesús en su ambiente -el Jesús judío-, ha sido puesta en primera línea en los presupuestos, pero no ha tenido gravitación en muchos de los resultados. 
A esta realidad de la diferencia y de la distancia histórica, viene a contraponerse otro elemento necesario para la búsqueda histórica: la analogía. Este principio, que se sostiene sobre la base de la constatación de que «las cosas deben funcionar siempre igual en el mundo» - siendo que el pasado es análogo al presente-, fue caracterizado primeramente por Ernst Troeltsch. Por analogía se entiende que el método histórico supone la convicción de que el entendimiento de los datos del pasado tiene como condición de posibilidad la homogeneidad de la naturaleza humana: «todos los hombres [a lo largo de la historia] han pensado, sentido y querido lo que nosotros mismos pensaríamos, sentiríamos y querríamos, de ser nuestras circunstancias similares a las suyas». ${ }^{4}$

Desde esta perspectiva, y en la aplicación a la investigación Jesuanica, al historiador le es posible entrar en la experiencia de fe de los primeros seguidores, aunque no la comparta. Un método histórico que no entre empáticamente en el tema de su estudio difícilmente podrá - en opinión de Dunn - captar la experiencia vital de los personajes históricos estudiados.

Sin embargo, esta característica analógica tiene sus limitaciones. Gadamer, que había criticado la intención del historicismo de superar la distancia histórica, también lo acusa de su ingenuidad en orden a lo analógico pues la "nivelación" que puede seguirse del principio de analogía - en cuanto que «las cosas deben funcionar siempre igual en el mundo»-, puede dejar cualquier experiencia extraordinaria en el ámbito de lo sospechoso. ${ }^{5}$ Por ende, si se aplica en extremo, no deja espacio para la novedad, aunque realmente hubiese ocurrido. De este modo, sentido del pasado - distancia y diferencia - y analogía son, por tanto, complementarios e invitan al ejercicio interpretativo de la hermenéutica. ${ }^{6}$

4 Antony Thiselton, The Two Horizons: New Testament Hermeneutics and Philosophical Description with Special Reference to Heidegger, Bultmann, Gadamer, and Wittgenstein (Michigan: Grand Rapids, 1980), http://www.obinfonet.ro/docs/herm/hermex/thiselton-2 horizons.pdf., 69.

5 Cf. Hans Georg Gadamer, Verdad y método (Salamanca: Sigueme, 19998), 438.

6 «Existe una verdadera polaridad de familiaridad y extrañeza, y en ella se basa la tarea de la hermenéutica [...] También aquí se manifiesta una tensión. La posición entre extrañeza y 


\subsubsection{Probabilidad y objetividad}

Una de las características que no puede ser pasada por alto y tiene relación con la labor del historiador en su etapa reconstructiva es que la reconstrucción no es idéntica a los acontecimientos sucedidos. James Dunn utiliza una división entre «acontecimiento, datos y hechos», donde los acontecimientos pertenecen al «irrecuperable pasado».7 El historiador puede tener a su alcance los "datos" y, con ellos, una reconstrucción de los "hechos". De esta manera, los hechos siempre son una interpretación de los datos.

Esto significa que las reconstrucciones históricas - hechosnunca pueden ser equiparables a lo que realmente sucedió (como pretendía en el siglo XIX Leopold von Ranke) - acontecimientos. Entre hechos y acontecimientos hay una aproximación. Dicha aproximación depende de la cantidad y seguridad de los datos, pero también del trabajo del investigador. Podríamos decir que los hechos contienen en sí la lejanía del acontecimiento y la analogía de la interpretación. Cuando los datos son fragmentarios, inconexos o inseguros la aproximación será más difícil y, también, más insegura. De este modo, en el trabajo histórico siempre nos encontraremos con probabilidad, y escalas en esta proximidad. Los hechos pueden ser "casi ciertos", "muy probables", " probables", "verosímiles", etc., pero siempre tendrán en sí la constante de una provisionalidad que está a la espera de nuevos datos e interpretaciones. En el ámbito de la historia, la probabilidad (un hecho es "probable") es una apreciación muy positiva. ${ }^{8}$

La búsqueda de la objetividad, en cambio, está marcada por la concepción historicista de la construcción del método histórico. Éste se construyó sobre la base del modélico método científico decimonónico, manteniendo la visión de que los hechos históricos pueden ser

familiaridad que ocupa para nosotros la tradición es el punto medio entre la objetividad de la distancia histórica y la pertenencia a una tradición. Y este punto medio es el verdadero topos de la hermenéutica». Gadamer, Verdad y método, 364.

7 Cf. J.D.G. Dunn, Jesús recordado, 136-137.

8 Cf. Ibid., 137. 
considerados entes objetivos y, por tanto, la investigación histórica puede tender a dicha objetividad.

La tensión entre la búsqueda y sus posibilidades, en el ámbito de la objetividad histórica se mantiene a pesar de los avances de las investigaciones. El problema es la consideración ingenua de una objetividad plena. Dunn cita, en este sentido, a Edmund Husserl, mediado por Gadamer:

"La ingenuidad de hablar de "objetividad" prescindiendo por completo de la subjetividad que conoce, que lleva a cabo cosas reales, concretas; la ingenuidad del científico al que interesa la naturaleza, el mundo en general, y que es ciego al hecho de que todas las verdades que él adquiere como objetivas, y el mismo mundo objetivo en que se basan sus fórmulas, son su construcción vital, que se ha desarrollado dentro de él, esa ingenuidad, digo, ya no es posible cuando la vida entra en escena».

Admitir en el proceso de la labor histórica la mediación interpretativa y el carácter provisional de ésta no lleva a un relativismo histórico - en el sentido escéptico del término- que niegue la objetividad de lo ofrecido al conocimiento, sino que significa entender que en ese proceso de comprensión es inevitable la subjetividad: esta es una tensión que también reclama el ejercicio de la hermenéutica.

\subsubsection{El camino historiográfico: el realismo crítico}

Después de poner en evidencia las posibilidades del trabajo histórico, James Dunn formula una sentencia que informa de la opción en su trabajo como historiador: «Por ello, en lo que sigue intentaré practicar el arte del historiador siguiendo en alguna medida el modelo del "realismo crítico" $\gg .{ }^{10}$

Ahora bien, ¿qué es este realismo crítico en el ámbito de la historia? El realismo positivista (o ingenuo) asumía que lo conocido se corresponde exactamente con la realidad, sin más; y el idealismo 
ponía demasiado énfasis en lo subjetivo del conocer. El realismo crítico propugnado por Bernard Lonergan, mantiene la tensión entre ambos - realismo ingenuo e idealismo - en una síntesis que comprende el proceso de conocimiento no sólo en el «percibir, sino más bien en la conjunción de experiencia, entendimiento y juicio». ${ }^{11}$

El encargado de llevar esta concepción al ámbito de los estudios bíblicos fue Ben Meyer reformulando el argumento de Lonergan: «lo que caracteriza al realismo crítico es su insistencia en que lo empírico (los datos), lo inteligente (las preguntas y respuestas), lo racional (la percepción de los datos como suficientes o insuficientes, el acto de adhesión personal) entra todo ello en un verdadero juicio». ${ }^{12}$

\section{Las consecuencias hermenéuticas: el sentido hermenéutico de la distancia histórica, de la probabilidad y la concepción de lectura}

\subsection{El sentido hermenéutico de la distancia histórica y la probabi- lidad: «el sentido llano»}

La profundización del giro lingüístico desde mediados del siglo XX - en el llamado posmodernismo - llevó el tema de la hermenéutica hacia una infinidad de interpretaciones a través de la descontextualización del texto. La lectura se consideró libre de las ataduras de su autor y de las ataduras que le imponía su ambiente.

Tal modelo interpretativo intentaba "liberar" el significado del texto renunciando al que su autor le quiso dar al momento de la escritura. Sin embargo, esta opción metodológica olvida la

11 Cf. Ibid., 145.

12 Ben F. Meyer, Reality and Illusion in New Testament Scholarship: A Primer in Critical Realist Hermeneutics (Oregon: Liturgical Press, 1994). Una formulación de N. T. Wright también ayuda a entender el porqué de la denominación realismo crítico: «Ésta es una manera de describir el proceso de conocimiento que tiene en cuenta la realidad de la cosa a conocer como algo distinto del sujeto cognoscente (por tanto, 'realismo'), aunque admitiendo absolutamente que el único acceso posible a esa realidad se halla en el sinuoso camino del adecuado diálogo o conversación entre el sujeto cognoscente y la cosa a conocer (por tanto, 'crítico')》. N.T. Wright, The New Testament and the People of God (Minneapolis: Fortress Press, $1997^{2}$ (orig. 1992)), 35. 
distancia y la diferencia histórica que hacen posible cualquier estudio historiográfico y el valor que éstas tienen en el trabajo hermenéutico. Por este motivo, Dunn proclama que los textos históricos deben ser considerados como tales. Para nuestro autor los textos tienen derecho a su identidad como fue determinada por el autor o por el proceso del que resultó su forma permanente. Además, la misma tradición exige el respeto de tal característica ya que, en el caso de la investigación histórica de Jesús, los textos que se usan como fuentes desde el principio fueron reconocidos intencionales en forma y sentido como "evangelios". En este sentido, Dunn propugna la sentencia de Gadamer: «aplicar al mundo histórico lo que desde siempre ha sido un fundamento de toda interpretación textual: que cada texto debe ser comprendido desde sí mismo». ${ }^{13}$ De esta manera, se proclama que el texto debe ser respetado y permitirle que hable con su propia voz.

Los textos siempre son vistos como un vehículo para la comunicación consciente de ideas. Cualquiera que considere escribir algo lo hace bajo la presuposición de que con sus palabras y frases trata de transmitir un pensamiento, y logrará tener éxito en su empresa. Así, el principio del "sentido llano" pretende tener en cuenta el contexto histórico, las circunstancias, los géneros, etc.

De esta manera, trata de descubrir en el texto las posibilidades de extraer el significado y alcanzar un acuerdo amplio sobre el sentido básico de ese significado. En hermenéutica, y por tanto en el trabajo histórico, no se considera el significado como algo objetivo y, entonces, la "reconstrucción" del significado histórico en el contexto histórico es una labor a base de probabilidades y aproximaciones, cuyo éxito estará basado en la cantidad de datos que se tengan a disposición. El "sentido llano" está en la base de un trabajo hermenéutico que busca aproximaciones válidas de significado, del cual se puede alcanzar un consenso que se manifieste como lectura básica. De este modo, el "sentido llano" se encuentra entre dos 
extremos: la pura objetividad (que quiere cercenar la posibilidad de interpretación y obtener un significado único) y la pura relatividad del significado (que no considera ninguna posibilidad de entender un significado básico y estable en la comunicación).

Lo que intenta el sentido llano es poner en el centro el texto como expresión de la intención de comunicar y como acto comunicativo entre el autor y los pretendidos lectores, pues el escritor no escribe por escribir, sino pensando en cómo va a ser recibida esa comunicación. Por ende, "el sentido llano" se encuentra también en la consideración tanto del momento de inspiración, como en la atención del momento de la recepción. De este modo, abre a la posibilidad de reconocer el valor histórico del texto y de su significado.

\subsection{El modo de leer: La concepción de lectura}

En lo anterior ya se logra ver la imbricación entre la labor histórica y la labor hermenéutica. Ambas disciplinas van "girando" en un círculo que va profundizando en el conocimiento o la comprensión. Por cercanía y exigencia, la tarea interpretativa debe ser compañera de la labor histórica. En este sentido, a Dunn le parece indicado resaltar los aportes de Gadamer en dos sentidos: el de la historia efectual (Wirkungsgeschichte) y el de la fusión de horizontes.

No es difícil descubrir el porqué de la importancia de los aportes de Gadamer, ya que éstos pueden hacer entrar en el trabajo histórico la importancia de la tradición, desechados en algunos presupuestos historiográficos. Entre el texto y el lector media una distancia que no es una realidad vacía, sino que está llena de efectos, de tradición intermedia. Ésta no debe ser superada sino aprovechada como una realidad positiva que facilita el entendimiento. Esto posibilita que la fe no sea vista como reñida con el proceso hermenéutico en su aplicación a los estudios históricos del Nuevo Testamento. 
El otro aporte es el de la fusión de horizontes: Gadamer entiende la comprensión como un proceso de fusión de dos horizontes, el de aquello que se quiere entender y el horizonte histórico en el que se sitúa el intérprete. ${ }^{14}$

De esta manera, el valor es doble en la medida que se afirma y reconoce el hecho de la distancia entre el intérprete y el texto, y porque el proceso hermenéutico es considerado más que un simple sentimiento romántico de empatía con el autor. Se unen los momentos que mencionamos más arriba: la distancia y la analogía, la alteridad del texto - con el respeto de su autonomía - y la implicación del intérprete - que a su vez se conoce a sí mismo.

Dunn prefiere ver en esto, más que un círculo, un diálogo:

«Aunque prefiero representarme la hermenéutica como un 'diálogo', no se me escapan los aspectos importantes que se desprenden del círculo hermenéutico. Simplemente encuentro más atractiva la imagen del diálogo a modo de encuentro personal, en parte porque refuerza el concepto de la hermenéutica como una especie de proceso de formación personal, y en parte porque reconoce el texto como acto comunicativo. Digamos, pues, que la hermenéutica es un diálogo en el que se deja hablar libremente a los interlocutores, en vez de un interrogatorio del texto en el que éste puede solamente responder a las preguntas que se le formulan. Por exponer la misma idea desde otro ángulo: para que el diálogo sea fructífero tiene que haber además una intensa discusión del intérprete con el texto. Aquí también nos hemos alejado conscientemente del antiguo paradigma científico de investigación fría, desapasionada, según el cual había que tratar el texto como si fuera una especie de cadáver en la sala de anatomía patológica a la espera de ser diseccionado con los escalpelos del método histórico». ${ }^{15}$

14 «...] comprender una tradición requiere sin duda un horizonte histórico. Pero lo que no es verdad es que este horizonte se gane desplazándose a una situación histórica. Por el contrario, uno tiene que tener siempre su horizonte para poder desplazarse a una situación cualquiera. [...] una conciencia verdaderamente histórica aporta siempre su propio presente, y lo hace viéndose tanto a sí misma como a lo históricamente otro en sus verdaderas relaciones. Por supuesto que ganar para sí un horizonte histórico requiere un intenso esfuerzo. [...] Por eso es una tarea tan importante como constante impedir una asimilación precipitada del pasado con las propias expectativas de sentido. Sólo entonces se llega a escuchar la tradición tal como ella puede hacerse oír en su sentido propio y diferente». Ibid., 375-376

15 Dunn, Jesús recordado, 160. 


\section{Los aportes de la obra de Dunn}

\subsection{Una nueva aportación al objeto de estudio: El Jesús Recordado}

Los presupuestos historicistas colocaron la fe en Jesús al comienzo de la tradición postpascual. En esa realidad aparece la pregunta por el "Jesús histórico" como una suerte de rescate de la verdadera figura del Galileo. Es que Jesús - según la mirada de muchos autores involucrados en la Quest - habría sido transformado por la fe de la comunidad después de la Pascua.

En el mismo sentido, la Crítica de las Formas abrió la posibilidad de pensar más allá de las primeras fuentes escritas y puso de manifiesto que era la realidad de la fe la que configuró esas mismas fuentes. Sin embargo, el afán de intentar detallar el modo en que la fe había configurado las formas hasta darles la conformación final de los escritos neotestamentarios hizo que no se prestara atención a lo distintivo de esa fe, y a las implicancias que tendría tal tesis para la investigación histórica sobre Jesús. Otros, siguiendo la perspectiva general supusieron que esa fe ya era fe pospascual, dando por sentado que los relatos habían sido configurados desde la experiencia de la pascua. ${ }^{16}$ Otra problemática de la Crítica de las Formas está en la concepción, al igual que en los estudios historicistas, de que detrás de las formas hay un estado puro de tradición no "contaminado por la fe". La pregunta resultante es si habrá algún dato que no haya sido configurado por la fe desde el comienzo, y a qué tipo de fe nos referimos.

16 Heinz Schürmann señala con respecto a los representantes de la Formgeschichte: «La cuestión de la tradición reclama el método de la historia de las formas (Formgeschichte). Pero precisamente no parece ser éste un camino practicable, ya que sus representantes son prácticamente todos de la opinión de que la tradición no puede ir más allá de los intereses y necesidades de la comunidad: nunca puede, por tanto, responder a la cuestión del Jesús histórico.» Heinz Schürmann, "Comienzos prepascuales de la tradición de los logia, Selecciones de teología 9 (1970 (orig. 1962)), 17. 
Para Dunn, desde el principio lo que se expone ante nosotros es la realidad de un Jesús conocido por los efectos que produjo en sus seguidores. Los textos evangélicos no son biografías, ni tienen por finalidad presentar una información puramente histórica de Jesús. ${ }^{17}$ De hecho, el mismo Jesús es el que originó la fe de sus seguidores e inspiró una fe que encontró expresión tiempo después en los evangelios. De esta manera, los testimonios nos ponen frente al impacto que Jesús generó en sus seguidores; éstos - a su vez - manifestaron ese efecto formulando una tradición que también causa efecto. En este sentido, lo que manifiesta esa primera tradición es la interpretación que los discípulos de Jesús hicieron de la impresión que Él les causó. Dunn asume esta realidad al sostener que «la misma tradición en su forma más primitiva es, en un sentido decisivamente importante, creación de la fe; o, para ser más precisos, es el producto de los encuentros entre Jesús y los que se hicieron sus discípulos». ${ }^{18}$

De este modo, no existe un vacío entre un Jesús histórico y un Jesús fiducial, sino que ya desde el inicio surge una tradición desde unos encuentros que convertirán a los oyentes en creyentes, y éstos entendieron su llamado a ser discípulos como una pregunta de fe. De esta manera, las tradiciones más antiguas son fruto de una respuesta discipular, y por esto no hay razón posible de una búsqueda de un Jesús histórico detrás del Jesús de la fe: es el mismo Jesús el que provoca esa fe.

La tradición de Jesús surge como respuesta a un llamado a seguirlo, a escucharlo, a vivir con él, y se desarrolla desde el recuerdo de la impresión que esto produjo. Estos seguidores, viendo y oyendo al Galileo, realizaron una primera acción hermenéutica: «los exé- 
getas del siglo XX no empiezan el diálogo hermenéutico; continúan un diálogo que comenzó en la formación inicial de la tradición». ${ }^{19}$

Por tanto, lo importante de destacar es que los dichos o relatos son testimonio del impacto producido por Jesús. ${ }^{20}$ Tal impresión limita profundamente la idea - si no es que la desacredita - de una búsqueda de un Jesús que podría ser distinto a aquel que produjo fe en los suyos. Es el impacto producido por Jesús el que se presenta como punto de partida de cualquier indagación histórica:

«El punto de partida ineludible para cualquier búsqueda de Jesús debería ser el hecho histórico de que Jesús causó un impacto duradero en sus discípulos. Es posible considerar la profunda impronta que Jesús dejó en su misión como uno de los presupuestos históricos más seguros. [...] Resulta imposible explicar el hecho histórico del cristianismo sin el hecho histórico de Jesús de Nazaret y de la impresión que causó. Evidentemente, lo que dijo e hizo produjo una honda impresión en mucha gente, y tal impacto ha resonado a lo largo de la historia». ${ }^{21}$

Por este motivo, para Dunn la figura de Jesús no puede ser la de una persona anodina. El hecho de la invitación a un seguimiento que involucra un cambio de vida radical - abandono de la familia, del trabajo, de la cotidianeidad-, y la consecuente respuesta sólo puede deberse a una realidad implicada con la fe. Para el autor inglés no es importante una fundamentación epistemológica de esa fe, sino la caracterización de ésta con la terminología de "compromiso" y "confianza".

19 lbid.

20 J. Dunn cita expresiones próximas a la idea del impacto producido por Jesús de otros investigadores: «Similarmente P. Barnett, Jesus and the Logic of History (Grand Rapids: Eerdmans, 1997), se refiere al «percuciente impacto del Maestro Jesús» (56, 102, 127); cf. P. BARNET, Jesus and the Rise of Early Christianity, cap. 2. Patterson pone de relieve la "impresion (original)" causada por Jesús, la "experiencia" "creada" por Jesús en sus discípulos (The God of Jesus, 10 , 46-50, 53-54, 56-58, 87, 90, 113, 118, 130-31); cita a Willi Marxsen, "La fe cristiana empezó con el fenómeno de la impresión producida por Jesús" (56, n. 1) [...].». J.D.G. Dunn, El Cristianismo (l) 160 nota de pie 107. Cursivas en el original. También Schürmann muestra que Fr. Büchsel p. e. sostiene una impresión imponente de la figura de Jesús. Cf. H. Schürmann, Comienzos prepascuales, 19.

21 James D.G. Dunn, Redescubrir a Jesús de Nazaret: Lo que la investigación sobre el Jesús histórico ha olvidado (Salamanca: Sígueme, 2006), 27. 
Dicha fe no surgió con la Pascua, aunque seguramente fue iluminada y transformada por ella. Sin embargo, no puede dejar de señalarse, en el sentido de la existencia de una fe prepascual, que esa fe histórica modeló desde el principio la tradición de Jesús. Y esa tradición de los dichos y hechos de Jesús debería haber sido valiosa desde el encuentro con él y la fe puesta en él. Para Dunn es inverosímil creer que los discípulos guardaron secretamente las vivencias con el Galileo y que sólo cuando surgió la necesidad - a la luz de la Pascua - de recordar su figura histórica, por la exigencia de su vejez y de los evangelistas, comenzaron a entregar tales recuerdos a una tradición pospascual. Más lógico resultaría que quienes tuvieran una imagen favorable de Jesús recordaran sus propias historias sobre lo que escucharon y vivieron con él, sobre aquello que los impactó. Y esto según diversas necesidades, sea para justificar su creencia, su cambio de vida, o simplemente para confirmarse unos a otros en el seguimiento de las enseñanzas del Nazareno. ${ }^{22}$

Este modo de tradición ya da indicios de una perspectiva de Dunn que nos parece de las más valiosas, la recuperación de una manera de abordar la tradición oral: cómo funciona el recuerdo comunitario.

Lo importante de destacar en este punto es la categoría de impacto para determinar la existencia de una fe histórica - anterior a la pascua - que modeló la tradición de Jesús. Este impacto de expresión y comunicación oral - en el intercambio de experiencias definitivas en la vida de los seguidores - constituye, según la opinión de Dunn, un a priori convincente para entender el inicio de la tradición más primitiva de Jesús. ${ }^{23}$

Dicha tradición, que se modeló desde el encuentro discipular con Jesús, sería el impulso original para la creación de los textos. Ellos partieron del binomio de dichos de Jesús como fueron oídos y re-

22 En este punto se puede considerar el Sitz im Leben de la primitiva comunidad. Cf. Schürmann. "Jesús trae la última palabra de Dios en la última hora (los inicios prepascuales de la tradición de los logia II)», en: Scholtissek, Klaus (ed.), El destino de Jesús (Salamanca: Sígueme, 2003).

$23 \mathrm{Cf}$. Dunn, Redescubrir a Jesús, 30. 
cibidos y acciones de Jesús como fueron presenciadas y retenidas en la memoria (ambas partes de cada frase son importantes):

«la tradición de Jesús proporciona acceso inmediato no a un dicho o hecho objetivamente referido, ni sólo al producto final de la fe (de los años cincuenta, sesenta, setenta u ochenta), sino también al proceso entre ambos, a la tradición que empezó con el impacto inicial del dicho o la palabra o la acción de Jesús y que siguió influyendo a los transmisores intermedios de la tradición hasta cristalizar en la narración de Marcos, Mateo o Lucas. En suma, debemos tener muy en cuenta lo que hay de respuesta discipular en la tradición, así como la profundidad de ésta y su forma final». ${ }^{24}$

Para Dunn la tradición sinóptica atestigua, en este sentido, no tanto lo que Jesús hizo o dijo, sino la manera en que lo que hizo o dijo fue recordado por sus discípulos. Es el proceso del recordar lo que actualizaba el presente: «es precisamente el proceso de recordar lo que funde los horizontes de pasado y presente, haciendo que el pasado sea presente de nuevo (Vergegenwärtigung)». ${ }^{25}$ De esta manera, lo que se encuentra en la tradición sinóptica es el recuerdo de los primeros discípulos: «no el mismo Jesús, sino el Jesús recordado». ${ }^{26}$ Dunn reafirma, en una obra posterior, que esta clave debe ser la que oriente los estudios sobre Jesús:

«Sólo el Jesús a quien podemos ver y oír a través del influjo que tuvo, a través del impacto que produjo en sus primeros discípulos, tal como se muestra en las tradiciones que formularon y recordaron; sólo ese Jesús está a disposición del investigador. No obstante, y esto es lo que quiero destacar, este Jesús está a disposición del investigador». ${ }^{27}$

Por ende, la ilusión de que ese Jesús - el Jesús histórico - pudiese servir de "norma normans" para la interpretación de los textos evangélicos se desmorona con la constatación misma de que la tradición prepascual ya es una respuesta de fe de aquellos que

24 Dunn, Jesús recordado, 166-167.

$25 \mathrm{lbid}$. 167. Resulta interesante la aclaración que se hace en nota de pie 110 , citando a J. Schröter: «el recuerdo de las tradiciones de Jesús puede entenderse, en consecuencia, como un proceso selectivo mediante el que el presente actual adquiere sentido por referencia a la persona de Jesús».

26 lbid.

27 Dunn, Redescubrir a Jesís., 43. Cursivas en el original. 
sintieron la necesidad de guardar el recuerdo de las palabras y acciones del Galileo. Una de las censuras de Dunn contra el curso de las investigaciones se pronuncia en este sentido y protesta contra las reconstrucciones que acercan los investigadores al tratar de alejarse de los evangelios.

\begin{abstract}
«[...] la investigación ha estado demasiado tiempo cautivada por la quimera de un Jesús histórico, una figura objetiva artificial enterrada en los evangelios y esperando ser exhumada y blandida en alto, la cual es distinta de los evangelios; todo ello sin percatarse plenamente de que cuanto menos deba el Jesús reconstruido a la imagen que de él nos transmiten los sinópticos, más expresa las intenciones de los investigadores». ${ }^{28}$
\end{abstract}

La conciencia de que Jesús puede ser percibido solamente a través del impacto que causó en sus primeros discípulos se convierte en la clave para un reconocimiento histórico (y una evaluación) de tal impacto. La constatación de que ese impacto fue duradero, de que produjo una honda impresión en mucha gente y de que ha resonado a lo largo de la historia, debe convertirse en el punto de partida de la investigación sobre Jesús, pues es uno de los datos más seguros que se tiene en la indagación de la historia del Galileo. ${ }^{29}$ Este hecho que determina la existencia de una fe prepascual $y$, por tanto, la realidad de una tradición anterior a la Pascua sobre Jesús, resulta en algún tipo de solución para el "abismo" largamente observado entre historia y fe.

Por supuesto que luego podrá haber añadidos, iluminaciones desde la experiencia de fe pospascual, desarrollos de la tradición y adición de complejidades en la labor de transmisión. Sin embargo, lo que se debe resaltar es que, en la tradición sinóptica - en cuanto al contenido de lo que Jesús hizo y dijo-, se puede descubrir una

28 lbid.

29 Dunn es crítico con las investigaciones historicistas en esta consideración: «[...] la investigación sobre el Jesús histórico [...] ha sido incapaz de reconocer que el impacto generador de fe que Jesús tuvo en aquellos a quienes llamó al discipulado es el punto de partida apropiado - de hecho, el más obvio y necesario- para intentar "remontarnos" a Jesús. Ha sido incapaz de reconocer que la tradición de Jesús es el resultado directo de dicha impresión, y expresa la fuerza y naturaleza de esta, y constituye un claro testimonio de ese impacto.» /bíd., 43-44. 
«continuidad entre los recuerdos prepascuales y la predicación pospascual, una continuidad de fe». ${ }^{30}$

\subsection{El aporte de Dunn para un cambio paradigmático: del paradigma literario al paradigma de oralidad}

Dada la perspectiva de continuidad entre los testimonios prepascuales y pospascuales, la búsqueda del Jesús histórico se puede mostrar fecunda allí donde se valora la importancia de la tradición sobre Jesús. Dicha tradición, reconstruida desde el recuerdo de lo que Jesús hizo y dijo, se transforma así en el medio donde se transmiten las noticias que tenemos de Jesús y que luego se cristalizan en los textos que poseemos. Dunn sostiene que para la amplia mayoría de los investigadores la búsqueda debe situarse en esta convicción de que la clave de la investigación se encuentra en torno a dicha tradición.

La crítica que presenta el inglés a esta investigación es el carácter inadecuado con que, habitualmente, se ha concebido la tradición: el paradigma literario. Dunn observa que, en los dos últimos siglos de investigación la preocupación por las fuentes motivó un debate acerca de la fiabilidad de las mismas siguiendo una prerrogativa común: cuanto más primitiva sea la fuente, más fiable sería la información brindada. ${ }^{31}$ Esto se aplicó especialmente a los textos sinópticos dando por resultado el dominio, en el campo de estudio y en la investigación, de la hipótesis de los dos documentos siendo éstos documentos escritos. Incluso, señala Dunn, cuando se ofrecían algunas divergencias para explicar los problemas que aparecían en los datos siempre se pensaba en otros documentos escritos. ${ }^{32}$

Esta advertencia ante el paradigma literario ya había sido sostenida por B. H. Streeter en 1924, cuando reconocía la importancia

30 Dunn, Jesús recordado, 170.

31 Cf. Dunn, Redescubrir a Jesús., 50.

32 Como la referencia a un Ur-Markus o un proto-Lucas. Cf. Redescubrir a Jesús, 50 nota al pie 7 . 
de una "tradición oral viva" detrás de los evangelios y sostenía que el estudio del problema sinóptico no podía ser abordado «meramente como un problema de crítica literaria». ${ }^{33}$

Las perspectivas de la Formgeschichte, si bien avanzaron en la búsqueda de la tradición oral, corrieron en sintonía con la dependencia de una imaginación literaria. Wellhausen identificó el carácter oral de la tradición, pero indicó que ésta sólo estaba presente de modo disperso. Bultmann asumió el desafío, pero no pudo escapar de la mentalidad literaria: su pensamiento manifiesta la concepción literaria al identificar la tradición de Jesús con una tradición "compuesta de una serie de estratos", siendo el proceso imaginado como el de "capas" de tradición construidas unas sobre otras. Tal imagen está tomada del proceso de edición donde cada "capa" es una versión editada - para Bultmann, corregida y ampliada - de la "capa anterior". 34

En suma, si bien se reconoce la importancia de los procesos que atraviesan la tradición de Jesús en su producción, memoria y transmisión, los resultados de las metodologías empleadas suelen acercarse a la investigación con "mentalidad literaria". Esta perspectiva hace que se avance sobre los textos con diversas teorías que intentan explicar la tradición sin prestar atención al periodo oral o a cómo éste funcionaría. De este modo, la aproximación se produce en la búsqueda de explicaciones que eliminen la necesidad de una dependencia real del periodo de transmisión oral por considerarlo poco fidedigno. ${ }^{35}$ Este hecho produce un vacío entre Jesús y la tradición puesta por escrito.

33 Burnett Hillman Streeter, The Four Gospels: A Study of Origins, Treating of the Manuscript Tradition, Sources, Authorship, \& Dates (London: Macmillan, $1930^{4}$ (orig. 1924)), 229. Otro ejemplo de esto es William Farmer que se había opuesto a la prioridad marcana desde la hipótesis de que Marcos había copiado desde Lucas y Mateo: esta idea de copiado resalta aún más la concepción literaria del estudio de la tradición y formación de los sinópticos. Los mismos presupuestos de perspectiva literaria están presentes en las obras de autores como Goulder y Gooodacre. Cf. J.D.G. Dunn, Redescubrir a Jesús, 52-53.

34 Cf. Dunn, Jesús recordado, 238. Esta misma idea reaparece en Funk, como señala Dunn en nota de pie 116 ; cf. J.D.G. Dunn, Redescubrir a Jesús., 52-53.

35 Como señala José Carlos Caamaño, desde la ilustración - siendo uno de los problemas de ésta - se trasladó la oralidad al ámbito de la conciencia precrítica y se ubicó el hecho escrito-textual en el ámbito de la conciencia ilustrada. Cf. Jose Carlos Caamaño, «Los relatos populares y su dinámica testimonial», en Universidad Católica Argentina, Memoria identidad y reconciliación, Actas del congreso hacia bicentenario (Buenos Aires: EDUCA, 2010), 703-707. 
Y si además se agrega a ello la desconfianza innata - en la mentalidad literaria - del proceso de oralidad, el vacío se convierte en una brecha insuperable. Sobre esto se pronuncia Dunn:

«Según mi opinión, ésta es la [...] gran deficiencia en la investigación sobre el Jesús histórico: la comprensión de la transmisión de la tradición sobre Jesús exclusivamente desde el paradigma literario que nos resulta innato; la desgana a la hora de tomar en serio la cuestión de si la tradición oral se habría desarrollado como la tradición literaria; una valoración negativa de la tradición oral en relación con su fiabilidad como testimonio sobre Jesús; $\mathrm{y}$, consecuentemente, un juicio negativo en relación con la capacidad de los investigadores para decir algo sobre Jesús que inspire confianza.

¿Es posible remediar este serio desequilibrio en perspectiva y método? Creo que sí». ${ }^{36}$

\subsection{El aporte de Dunn en la construcción metodológica}

El cambio de un paradigma literario, como lo llama Dunn, a un paradigma oral implica necesariamente un modelo metodológico para llevar adelante la investigación sobre la vida de Jesús. Con una propuesta metodológica, se harían más elocuentes las posibilidades de entendimiento de la tradición, tanto en lo que respecta al contenido como a la transmisión, y también al entresijo de ambas: su interpretación.

Es cierto que, para el periodo oral, se han estudiado los modelos existentes en Medio Oriente. Desde la escuela rabínica - en la transmisión palabra por palabra que podría considerarse una tradición oral controlada formalmente: formal en el sentido de que existen maestros claramente identificados, y controlada porque el aprendizaje del material se da por el ejercicio memorístico y se la conserva como tradición, para preservarla íntegra-hasta las posibilidades de una transmisión informal - tradición informal no controlada: informal por no existir maestros determinados y no controlada porque no 
tiene resguardo en el sentido de tradición-. La escuela escandinava se dedicó al primero y la Formgeschichte al segundo. ${ }^{37}$

Entremedio de ambas surgía una posibilidad que había teorizado C.H. Dodd como recurso a una tradición oral confiable y a la vez no tan rígida como las memorizaciones de las escuelas rabínicas que dieran paso a las explicaciones posibles en cuanto a las diferentes versiones de los textos evangélicos. Pero de dicha posibilidad no se habían encontrado resquicios hasta las investigaciones que presentó Kenneth Bailey en un artículo del Asia Journal of Theology en 1991. En dicho artículo, Bailey encontró la posibilidad de esta posición intermedia en su experiencia de lo que las comunidades de Medio Oriente llaman haflat samar. Los haflat samar son reuniones que tienen las comunidades donde se transmiten las tradiciones que mantienen la identidad comunitaria. Su ambiente es informal, en el sentido de que no existe un maestro fijo ni un alumno identificado. Sin embargo, existen controles pues solamente quienes han crecido escuchando las historias pueden recitarlas en las reuniones públicas del pueblo y la comunidad que observa la recitación de la historia puede reprobar la representación si se cambia algo que no se puede variar en dicha tradición. Así logra mostrar la existencia de una tradición informal controlada que puede mantenerse en el tiempo y que, además, presenta una configuración de elementos rígidos y flexibles a la hora de ser transmitida.

Dentro de este tipo de transmisión, Bailey enumera cinco tipos de materiales: proverbios medulosos, enigmas en forma de historia, poesías, parábolas o historias y acontecimientos de la historia del pueblo o comunidad. En cada caso existe una regulación más o menos rígida según el material que se esté recitando. Bailey lo presenta en tres niveles:

37 Cf. K. BAILEY, «Informal controlled oral tradition and the synoptic Gospels» en: Asia Journal of Theology 5 (1991), 34-54. La versión que usamos es la reimpresión en: Themelios 20.2(1995), 4-10. 
- ninguna flexibilidad: poemas y proverbios en los que no se admiten variaciones ni en la terminología utilizada.

- alguna flexibilidad: parábolas y recuerdos de acontecimientos y personas importantes para la identidad del grupo. No se pueden introducir cambios en las líneas principales, pero se admite flexibilidad en los detalles;

- flexibilidad total: cuando el material no atañe a la identidad del grupo y no es juzgado instructivo ni valioso (caen en esta categoría los chistes, las noticias de la calle, etc.).

Una consideración posterior de Bailey conviene al modo como ingresa a la tradición el material nuevo: estos elementos deben reunir algunas consideraciones importantes para la comunidad y generar un impacto en ella. A través de ejemplos, Bailey muestra la fortaleza de la tradición informal controlada en Oriente Medio.

Dunn retiene como conclusiones del artículo de Bailey tres aspectos de la tradición informal controlada:

«Lo que añade Bailey es valioso, sobre todo el reconocimiento de que: 1) una comunidad puede estar lo bastante vinculada a sus tradiciones como para ejercer algún control sobre ellas; 2) el grado de control puede variar según la forma de la tradición y según la importancia de ésta para la identidad comunitaria, y 3) el elemento del relato considerado como su núcleo o la clave de su significado puede ser su parte más fija». ${ }^{38}$

La cuestión que prosigue es, por tanto, si es posible que esta configuración de la transmisión oral ofrezca un modelo para interpretar la tradición de Jesús. En opinión de Dunn, la aportación de la tradición informal controlada puede servir para la búsqueda de la tradición de Jesús, pues se puede comprobar la existencia en los textos sinópticos de algunos indicios de esta configuración de la memoria comunitaria.

A la luz del análisis de algunos textos, Dunn logra hacer una mostración de cómo la búsqueda de esquemas fijos y variables puede 
aplicarse a la tradición de relatos y dichos de Jesús, permitiendo sostener una comprensión oral de la transmisión de la tradición. La aplicación metodológica consiste en poner en columnas los paralelos y establecer cuáles son los núcleos fijos y cuales los elementos variables. Miremos gráficamente la metodología con un pasaje: ${ }^{39}$

\begin{tabular}{|c|c|c|}
\hline Mateo 26,39 & Marcos 14,35-36 & Lucas $22,41-42$ \\
\hline $\begin{array}{l}\text { Y adelantán- } \\
\text { dose un poco, cayó } \\
\text { rostro en tierra y oró } \\
\text { diciendo: } \\
\text { "Padre mío, } \\
\text { si es posible, pase } \\
\text { de mi este cáliz. Sin } \\
\text { embargo, no sea } \\
\text { como yo quiera, sino } \\
\text { como quieras tu" }\end{array}$ & $\begin{array}{l}\text { Y adelantándose } \\
\text { un poco, cayó en tierra y } \\
\text { rogaba que, si fuera po- } \\
\text { sible pasará de él aque- } \\
\text { lla hora. Y decía: "Abba, } \\
\text { Padre todo es posible } \\
\text { para ti. Que pase de mí } \\
\text { este cáliz. Pero no sea lo } \\
\text { que yo quiero, sino lo } \\
\text { que quieras tá" }\end{array}$ & $\begin{array}{l}\text { Y se apartó de } \\
\text { ellos como un tiro de } \\
\text { piedra, y se arrodi- } \\
\text { lló, lloraba diciendo: } \\
\text { "Padre, si quieres, } \\
\text { que pase de mí este } \\
\underline{\text { cáliz. Sin embargo, }} \\
\text { no se haga mi volun- } \\
\text { tad, sino la tuya" }\end{array}$ \\
\hline
\end{tabular}

En subrayado aparece lo que es común, y, sin subrayado, lo variable. Es claro, con este simple ejemplo, que no se puede esperar en estos textos redacciones anteriores, ya que los cambios son muy marcados. En cambio, según sostiene Dunn, descubrir en ellos una raíz oral con un núcleo fijo para lo más importante, y un esquema flexible para lo que está sujeto a variaciones, tiene más probabilidades de verosimilitud. Además, más allá de que no haya una concordancia palabra por palabra sí se retiene la idea principal, algo propio de la transmisión oral controlada.

Otra sinopsis nos mostrará un esquema con mayor cantidad de puntos rígidos y menos elementos flexibles:

39 Los pasajes los elegimos al azar, pues nuestra meta no es más que la mostración gráfica del modelo de interpretación que Dunn lleva a cabo a lo largo de su obra. En este caso, los análisis están tomados de J. D. G. Dunn, Jesús recordado, 802 y 804 respectivamente. 


\begin{tabular}{|c|c|}
\hline Mateo $11,25-26$ & Lucas 10,21 \\
\hline${ }^{25}$ En aquel tiempo dijo Jesús: & ${ }^{21}$ en aquella misma hora se- \\
\hline Te alabo, Padre, Señor del & sionó Jesús de gozo en el Espíritu \\
\hline cielo y de la tierra, porque has & Santo, y dijo: Te alabo, Padre, Se- \\
\hline ocultado estas cosas a los sabios & ñor del cielo y de la tierra, porque \\
\hline y a los inteligentes y se le has re- & has ocultado estas cosas a los sa- \\
\hline velado a los pequeños. ${ }^{26}$ Sí, Padre, & bios y a los inteligentes y se le has \\
\hline pues tal ha sido tu voluntad & revelado a los pequeños. Si, Padre, \\
\hline
\end{tabular}

Esta metodología que Dunn utiliza a la hora de identificar la tradición de Jesús conlleva también algunas consideraciones en torno a la hipótesis del Jesús recordado y su sustentabilidad en la perspectiva oral de la tradición.

Posibilidades de la perspectiva oral de la tradición

y la aplicación del modelo de la tradición informal controlada

La consideración del paradigma oral permite conjeturar - según hace Dunn - una genética de la transmisión de la tradición de Jesús. La consideración de la memoria colectiva como recuerdo de transmisión oral permite el entendimiento de que lo recordado en las transmisiones estuviese marcado por la profundidad del impacto que Jesús causaba en su actuación. El mismo impacto conllevaría la necesidad de la formación de una tradición que recordara qué lo había causado: «al producir su efecto, la palabra o el hecho impactante devino tradición de esa palabra o hecho». ${ }^{40}$ Es este impacto causado el que daría a la tradición su estructura como consecuencia de las

40 Dunn, Jesús recordado, 288. Nuestras negritas son cursivas en el original. Además de cita - en el mismo sentido- en nota al pie 267 a Charles Kingsley Barrett, Jesus and the Gospel Tradition (London: SPCK, 1967).: «La tradición se originó más en la impresión causada por la persona carismática que en dichos aprendidos de memoria» «se conservó porque no podía ser olvidada». 
indicaciones, las palabras fundamentales o la parte más álgida de la historia contada o del hecho sucedido.

Otra consideración se da en la transmisión como hecho comunitario. Habitualmente se entiende desde la perspectiva literaria que, en el ambiente de la investigación, se deben buscar los testimonios particulares de la actuación de Jesús. La perspectiva de la oralidad en tanto paradigma, en cambio, invita a hacer el esfuerzo de entender el proceso de formación de la tradición como un asunto comunitario:

\begin{abstract}
«Así como una experiencia compartida del impacto causado por Jesús reunió primero un número de individuos en el discipulado, del mismo modo la formulación de ese impacto en palabras compartidas contribuyó sin duda a que ellos estrecharan sus lazos formando una comunidad de discípulos. Ya en el círculo prepascual de discípulos era 'una comunidad de confesión' (Bekenntnisgemeinschaft) constituida por discípulos comprometidos ( $\mathrm{Nach}$ folgenden Jüngern) que confesaban que Jesús era el revelador e intérprete final de la palabra de Dios». ${ }^{41}$
\end{abstract}

De este modo, el carácter de memoria compartida - propio de la transmisión oral- hace que lo que se encuentre en la tradición de Jesús sean los rasgos constantes y coherentes del impacto compartido: «Hay ciertamente un Jesús que produjo tal impacto, el Jesús recordado, pero no una forma pura original». ${ }^{42}$

Esta perspectiva oral que se asienta en el impacto producido y compartido lleva también una consideración de la formación primitiva de la tradición de Jesús. No puede, sin más, sostenerse la existencia de una tradición informal al comienzo que solamente es tomada en serio luego de la Pascua, sino que la formación de la comunidad estaba ya en estado germinal desde la primera llamada del Galileo a sus discípulos más cercanos. La tradición formativa tiene que haber desempeñado desde entonces un papel importante en el proceso de seguimiento, ya sea en el compartir los hechos del 
llamado, como en la identidad de los grupos de seguidores. Por otra parte, es en este sentido que se puede encontrar en el seno de las comunidades primitivas una continua función desempeñada por testigos transmisores reconocidos desde el principio como apóstoles o portadores autorizados de la tradición de Jesús. En la misma línea aparecen las situaciones vitales de dicha comunidad que exigen pensar en el contenido de las misiones encomendadas por el Maestro de Galilea.

Ciertamente que la Pascua puede haber cambiado la perspectiva desde la que se recordaba aquella tradición, pero la tradición oral debe haber proporcionado un vínculo vivo con el ministerio de Jesús y por eso debió ser altamente valorada. En este sentido, la aplicación de la metodología propuesta por Dunn ayuda a encontrar ecos de aquella tradición prepascual. Si no se busca establecer "formas puras de tradición" en el sentido de "originales sueltos", no es por falta de información, sino porque tales "originales" corresponden a una perspectiva literaria de la transmisión de lo que Jesús hizo y/o dijo. Eso no niega que la tradición esté ahí, al alcance, y tampoco obliga a pensar en transformaciones que nos alejen de la actuación del Señor. La tradición oral se convierte en un puente para llegar a los textos:

«En transmisión oral, una tradición se recita, se interpreta, se representa, es decir, se ofrece en audición; pero no se edita. Y como hemos visto, las audiciones contienen elementos de estabilidad y elementos de variabilidad [...] mientras que el concepto de estratos literarios implica una lejanía cada vez mayor de un estrato 'original', 'puro' o 'autentico', el concepto de audición supone la entrada en contacto directo - incluso la inmediatez de interacción - con la parte nuclear de un tema vivo, aunque diversamente ataviado en las distintas audiciones»». ${ }^{43}$

«En otras palabras, lo que hoy día encontramos en los evangelios no es el estrato superior (última edición) de una serie de capas cada vez más impenetrables, sino la tradición viva de la celebración cristiana, que nos lleva con sorprendente inmediatez a lo central de los primeros recuerdos conservados de Jesús». ${ }^{44}$ 
Por último, una preocupación en la obra de Dunn se presenta frente a la suposición "desafortunadamente generalizada" de que cada documento refleja y representa los puntos de vista de una sola comunidad y que las tensiones existentes dentro de los documentos - y entre ellos - indican cristianismos diferentes - hipótesis que en otro lugar llama «un documento por comunidad» $»^{45}-\mathrm{y}$, por tanto, tradiciones opuestas: «Supone, en otras palabras, que más o menos desde el principio existieron corrientes de tradición diversas y antagónicas que celebraban diferentes Jesuses». ${ }^{46}$ Esta posición se encontraría relativizada si se supone la existencia de tradiciones orales que se comunicaban entre diversas comunidades: las primeras iglesias no estarían aisladas unas de otras en tradiciones enfrentadas, sino que en realidad parecerían ser una «red de comunidades en constante comunicación», realidad que parece atestiguada por las cartas de Pablo y los relatos de los Hechos de los Apóstoles.

\section{A modo de conclusión}

La obra de Dunn logra hacer aportes que dan posibilidad a entender la tradición o solo desde el componente historizante en la búsqueda de la vida de Jesús, sino que tengan en cuenta el valor de la tradición desde la perspectiva oral y comunitaria. Por otra parte, logra dar importancia a la perspectiva de tradición como contenido e interpretación, ya que otorga a la comunidad la capacidad de "controlar" que es tradición aceptada y que cosas, en cambio deben ser reprobadas.

Consideramos que la aportación es más grande que los resultados pues la obra de Dunn suele quedarse a la hora de analizar la historia de Jesús en algunos tópicos de la Quest, sobre los que creemos que el cambio de paradigma permite avanzar. Quizás lo más cuestionable de la aportación sea la exclusiva dependencia de 
la metodología con respecto a la múltiple atestiguación, lo que da mucho lugar a los sinópticos y puede hacer perder atención a la tradición joánica, aceptada por la comunidad y dejada de lado, las más de las veces, en la investigación.

Más allá de estas cuestiones los aportes que hemos mencionado en el articulo son lo suficientemente importantes para suscitar nuevas aproximaciones a la investigación sobre el Jesús histórico, el problema de la tradición y las maneras de acercarnos a los textos bíblicos a la hora de leerlos desde la investigación histórica. En este sentido nos parece que la obra magna del autor inglés es una obra de referencia en el tema.

\section{Bibliografía}

Barrett, Charles Kingsley. Jesus and the Gospel Tradition. London: SPCK, 1967.

Burke, Peter. The Reinassance Sence of the Past. Londres: Edward Arnold, 1969.

Caamaño, Jose Carlos. “Los Relatos Populares y su dinámica testimonial." Universidad Católica Argentina, edited by Memoria identidad y reconciliación Actas del congreso hacia el bicentenario, 703-07. Buenos Aires: EDUCA, 2010.

Dunn, James D.G. El Cristianismo En Sus Comienzos (I): Jesús Recordado. Navarra: Editorial Verbo Divino, 2009.

- Redescubrir a Jesús De Nazaret: Lo Que La Investigación Sobre El Jesús Histórico Ha Olvidado. Salamanca: Sígueme, 2006.

Gadamer, Hans Georg. Verdad y método. Salamanca: Sigueme, $1999^{8}$.

Meyer, Ben F. Reality and Illusion in New Testament Scholarship: A Primer in Critical Realist Hermeneutics. Oregon: Liturgical Press, 1994.

Schürmann, Heinz. "Comienzos Prepascuales De La Tradición De Los Logia.” Selecciones de teología 9(1970 (orig. 1962)): 17-29. 
—, Jesús trae la última palabra de Dios en la última hora (los inicios prepascuales de la tradición de los logia II), en: El destino de Jesús, editado por Klaus Scholtissek (ED.), Salamanca, Sigueme, 2003 (orig. 1960)

Schweitzer, Albert. Investigación Sobre La Vida De Jesús (Ii). Valencia: Edicep, 2002.

Streeter, Burnett Hillman. The Four Gospels: A Study of Origins, Treating of the Manuscript Tradition, Sources, Authorship, \& Dates. London: Macmillan, $1930^{4}$ (orig. 1924). https://biblicalstudies.org.uk/pdf/4gospels_streeter/complete.pdf.

Thiselton, Antony. The Two Horizons: New Testament Hermeneutics and Philosophical Description with Special Reference to Heidegger, Bultmann, Gadamer, and Wittgenstein. Michigan: Grand Rapids, 1980. http://www.obinfonet.ro/docs/herm/hermex/ thiselton-2horizons.pdf.

Wright, N.T. The New Testament and the People of God. Minneapolis: Fortress Press, $1997^{2}$ (orig. 1992). 